\title{
AlGaN/GaN HEMT-based fully monolithic X-band low noise amplifier
}

\author{
R. Schwindt ${ }^{1}$, V. Kumar ${ }^{1}$, O. Aktas ${ }^{2}$, J.-W. Lee ${ }^{3}$, and I. Adesida ${ }^{* 1}$ \\ 'Micro and Nanotechnology Laboratory and Department of Electrical and Computer Engineering, \\ University of Illinois at Urbana-Champaign, 208 N. Wright Street, Urbana, IL 61801, USA \\ 2 Department of Electrical and Electronics Engineering, Bilkent University, 06800 Bilkent, Ankara, \\ Turkey \\ ${ }^{3}$ School of Electronics and Information, Kyung Hee University, Suwon, 449-701, Korea
}

Received 13 July 2004, accepted 24 September 2004

Published online 8 February 2005

PACS 84.40.Dc, 84.40.Lj, 85.30.De, 85.30.Tv, 85.40.Qx

A fully monolithic AlGaN/GaN HEMT-based low noise amplifier is reported. The circuit demonstrated a noise figure of $3.5 \mathrm{~dB}$, gain of $7.5 \mathrm{~dB}$, input return loss of $-7.5 \mathrm{~dB}$, and output return loss of $-15 \mathrm{~dB}$ at 8.5 GHz. The de characteristics of individual $0.25-\mu \mathrm{m} \times 150-\mu \mathrm{m}$ transistors were: maximum current density of $1.0 \mathrm{~A} / \mathrm{mm}$, maximum transconductance of $170 \mathrm{mS} / \mathrm{mm}$ and a threshold voltage of $-6.8 \mathrm{~V}$. The devices have a typical short circuit current gain cutoff frequency of $24.5 \mathrm{GHz}$ and a maximum oscillating frequency of $48 \mathrm{GHz}$. The devices demonstrated a minimum noise figure of $1.6 \mathrm{~dB}$ with an associated gain of $10.6 \mathrm{~dB}$ at $10 \mathrm{GHz}$.

() 2005 WILEY-VCH Verlag GmbH \& Co. KGaA, Weinheim

1 Introduction Transmit/receive $(\mathrm{Tx} / \mathrm{Rx})$ modules for microwave radar and communication systems require both a power amplifier for the transmit function and a low noise amplifier (LNA) for the receive function. The performance, reliability, and manufacturability of next-generation military and commercial systems will be advanced through the integration of functionality on a single chip. Gallium nitride-based high electron mobility transistors (HEMTs) are excellent candidates for high power and low noise microwave signal amplification. This is due to the advantageous material properties of the group IIInitrides, such as wide bandgap (3.4 eV for GaN to $6.2 \mathrm{eV}$ for $\mathrm{AlN}$ ) leading to high breakdown fields (1-3 $\left.\times 10^{6} \mathrm{~V} / \mathrm{cm}\right)$ and high saturated electron drift velocity $\left(2.2 \times 10^{7} \mathrm{~cm} / \mathrm{s}\right)$. Also, the AlGaN/GaN heterostructure with its high conduction band offset and high spontaneous and piezoelectric polarizations exhibits high sheet carrier densities in the $10^{13} \mathrm{~cm}^{-2}$ range. As a result, very high microwave power performance has been demonstrated by AlGaN/GaN-based HEMTs [1-6]. Excellent microwave noise performance has also been demonstrated [7-9]. Because most research has focused on the high power performance of these devices, the only AlGaN/GaN HEMT-based low noise amplifier (LNA) reported until very recently was a hybrid circuit [10]. Very recently a few monolithic LNAs have been reported which operated below X-band or which employed sub-quarter micron gate-length devices or both [11-13]. This work reports a fully monolithic AlGaN/GaN HEMT-based LNA operating at X-band and employing a reliable $0.25-\mu \mathrm{m}$ gate-length technology. The results demonstrate the potential for the integration of a robust low noise amplifier with an ultra-high performance power amplifier in a single technology for next-generation military and communication systems.

2 Device and fabrication The layer used in the present study was grown on a semi-insulating 4H$\mathrm{SiC}$ substrate by MOCVD. The epilayer consists of a buffer, 2- $\mu \mathrm{m}$ undoped GaN, a 3-nm undoped

"Corresponding author: e-mail: iadesida@uiuc.edu, Phone: +1 217 333-3097, Fax: +1 217 244-6375 
$\mathrm{Al}_{0.25} \mathrm{Ga}_{0.75} \mathrm{~N}$ spacer, a 10-nm Si-doped $\left(\sim 1 \times 10^{19} \mathrm{~cm}^{-3}\right) \mathrm{Al}_{0.25} \mathrm{Ga}_{0.75} \mathrm{~N}$ charge supply layer, and a 10-nm undoped $\mathrm{Al}_{0.25} \mathrm{Ga}_{0.75} \mathrm{~N}$ barrier layer. The average sheet resistance of the sample was $453 \Omega /$ square. The first step for device fabrication was mesa-isolation using $\mathrm{Cl}_{2} / \mathrm{Ar}$ plasma in an inductively-coupled-plasma reactive ion etch (ICP-RIE) system. Ohmic contacts were formed by rapid thermal annealing of evaporated $\mathrm{Ti} / \mathrm{Al} / \mathrm{Mo} / \mathrm{Au}$ at $850{ }^{\circ} \mathrm{C}$ for $30 \mathrm{~s}$ [14]. The $0.25-\mu \mathrm{m}$ gate-length T-shaped gates $(\mathrm{Ni} / \mathrm{Au})$ were defined using electron-beam lithography. The transistors had a gate-width of $150 \mu \mathrm{m}$ and a source-drain spacing of $2.5 \mu \mathrm{m}$ and were passivated with $200 \mathrm{~nm}$ thick silicon nitride.

The integrated circuit fabrication process consisted of the following steps: mesa isolation, ohmic metal, Schottky gates via e-beam lithography, overlay metal, silicon nitride deposition and etch; nichrome resistor; a 1- $\mu \mathrm{m}$-thick evaporated gold level; and airbridge. In addition to active devices, this process incorporates steps necessary for the realization of passive elements, including low-loss transmission lines, metal-insulator-metal capacitors, spiral inductors, and thin-film resistors which are required for a complete monolithic microwave integrated circuit (MMIC) process. Because the LNA has relaxed requirements with respect to thermal impedance and source ground inductance compared to a high power amplifier, this initial LNA MMIC was designed using coplanar waveguide (CPW)-style transmission lines and passive elements so that backside processing was not required.

3 Device characteristics Figure 1 shows the DC performance characteristics of a typical $0.25 \mu \mathrm{m} \times$ $150 \mu \mathrm{m} \mathrm{AlGaN/GaN} \mathrm{HEMT.} \mathrm{It} \mathrm{has} \mathrm{a} \mathrm{maximum} \mathrm{drain} \mathrm{current} \mathrm{density} \mathrm{of} 1.0 \mathrm{~A} / \mathrm{mm}$ and a peak DC extrinsic transconductance of $170 \mathrm{mS} / \mathrm{mm}$. The threshold voltage is $-6.8 \mathrm{~V}$, where the threshold voltage was determined by extrapolating the drain current to zero from the maximum transconductance point.

The small signal and noise performance of a typical $.25 \mu \mathrm{m} \times 150 \mu \mathrm{m}$ AlGaN/GaN HEMT are shown in Fig. 2. Small signal characteristics were measured using an Agilent 8510B network analyzer. Figure 2(a) shows the short-circuit current gain $\left(\left|H_{2 l}\right|\right)$ and the maximum stable gain/maximum available gain (MSG/MAG) at the device's peak- $f_{T}$ bias point of $13 \mathrm{~V}$ drain-source voltage, $-6.0 \mathrm{~V}$ gate-source voltage and $34.6 \mathrm{~mA}$ drain current. The $f_{T}$ of the device is $24.5 \mathrm{GHz}$. The maximum frequency of oscillation $f_{\max }$ is $48 \mathrm{GHz}$ and is determined by extrapolating the maximum available gain (MAG) at $-20 \mathrm{~dB} /$ decade.

A Maury/ATN NP5 noise parameter measurement system along with an Agilent 8970B noise figure meter and $8971 \mathrm{C}$ noise figure test set was used to measure device noise parameters from 2 to $20 \mathrm{GHz}$. Figure 2(b) shows the device's minimum noise figure and associated gain at the device's minimum noise figure bias of $10 \mathrm{~V}$ drain-source voltage, $-6.7 \mathrm{~V}$ gate-source voltage and $10 \mathrm{~mA}$ drain current. The minimum noise figure at $10 \mathrm{GHz}$ is seen to be $1.6 \mathrm{~dB}$ with an associated gain of $10.6 \mathrm{~dB}$.

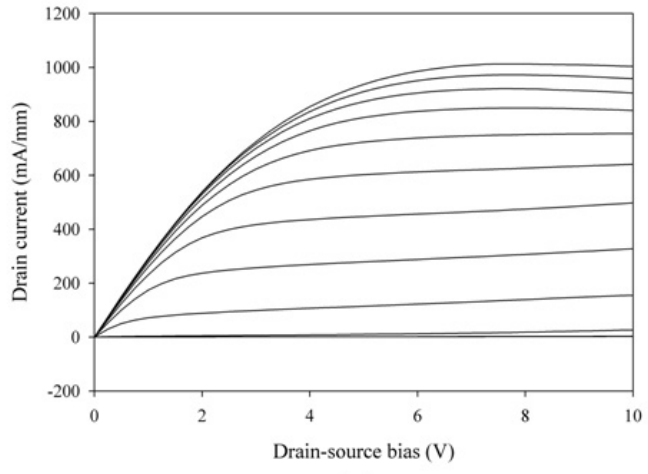

(a)

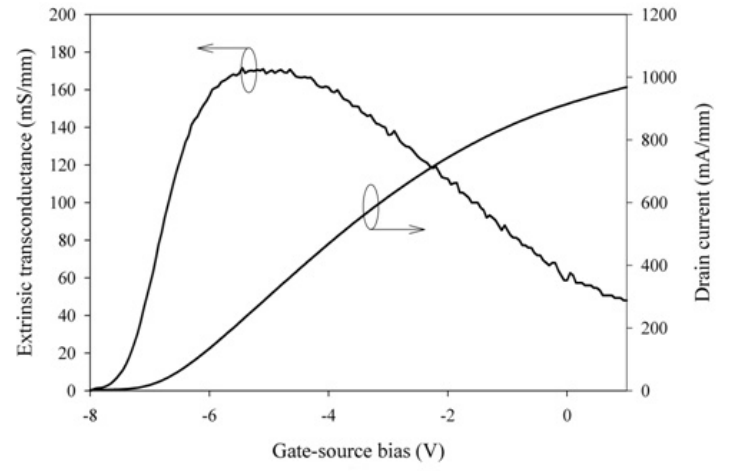

(b)

Fig. 1 (a) Drain current-voltage $\left(I_{D}-V_{D S}\right)$ characteristics of a typical $0.25 \mu \mathrm{m} \times 150 \mu \mathrm{m} \mathrm{AlGaN} / \mathrm{GaN}$ HEMT on SiC. (b) Transconductance characteristic of a typical $0.25 \mu \mathrm{m} \times 150 \mu \mathrm{m}$ AlGaN/GaN HEMT with $V_{D S}=8 \mathrm{~V}$. 


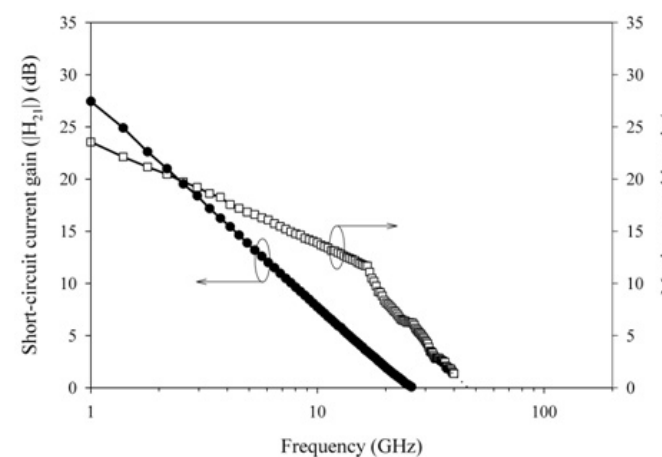

(a)

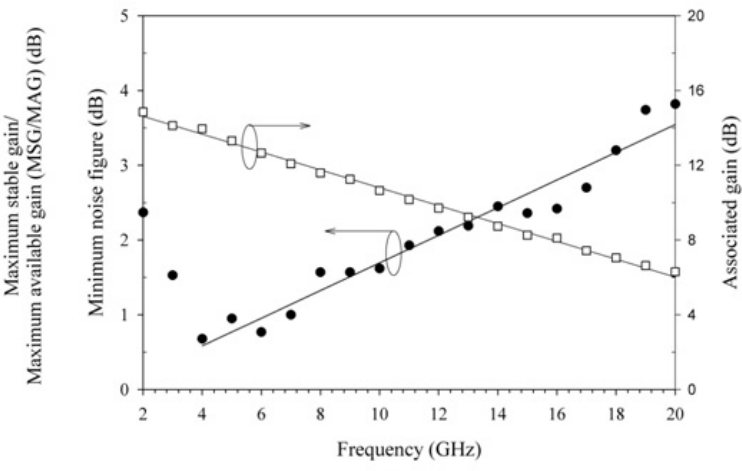

(b)

Fig. 2 (a) Small signal performance of a typical $0.25 \mu \mathrm{m} \times 150 \mu \mathrm{m} \mathrm{AlGaN/GaN} \mathrm{HEMT} \mathrm{on} \mathrm{SiC} \mathrm{at} \mathrm{the} \mathrm{peak-} f_{T}$ bias of $V_{D S}=13 \mathrm{~V}, I_{D}=13.6 \mathrm{~mA}$. (b) Minimum noise figure and associated gain of a typical $0.25 \mu \mathrm{m} \times 150 \mu \mathrm{m} \mathrm{AlGaN} / \mathrm{GaN}$ HEMT at the minimum noise bias of $V_{D S}=10 \mathrm{~V}, I_{D}=10 \mathrm{~mA}$.

4 Circuit performance A circuit schematic and a photograph of the LNA MMIC are shown in Fig. 3. The circuit is a single-stage design. Spiral inductors between the HEMT's source and ground provide series inductive feedback to bring the optimum noise bias $\Gamma_{o p t}$ closer to $S_{11} *$ to achieve acceptable input return loss while at the same time matching for the optimum noise performance. The output matching network was designed for optimum small signal gain.

The small signal gain and input and output return losses of the LNA MMIC are shown in Fig. 4. Across the 7 to $10 \mathrm{GHz}$ band, the gain exceeds $6 \mathrm{~dB}$ and the input and output return losses are below -7 $\mathrm{dB}$. The noise figure is less than $4.6 \mathrm{~dB}$ across the 7 to $10 \mathrm{GHz}$ with a minimum of $3.4 \mathrm{~dB}$ at $9.5 \mathrm{GHz}$. At $8.5 \mathrm{GHz}$, the circuit has a noise figure of $3.5 \mathrm{~dB}$, gain of $7.5 \mathrm{~dB}$, input return loss of $-7.5 \mathrm{~dB}$, and output return loss of $-15 \mathrm{~dB}$. The LNA was biased with a drain-source voltage of $8 \mathrm{~V}$ at a drain current of 40 $\mathrm{mA}$.

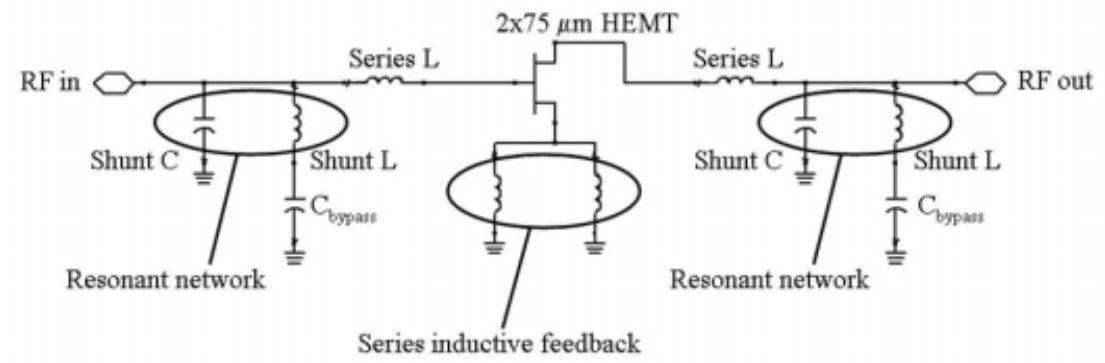

Fig. 3 (a) Schematic diagram of the monolithic AlGaN/GaN HEMTbased LNA. (b) Photograph of the LNA.

(a)

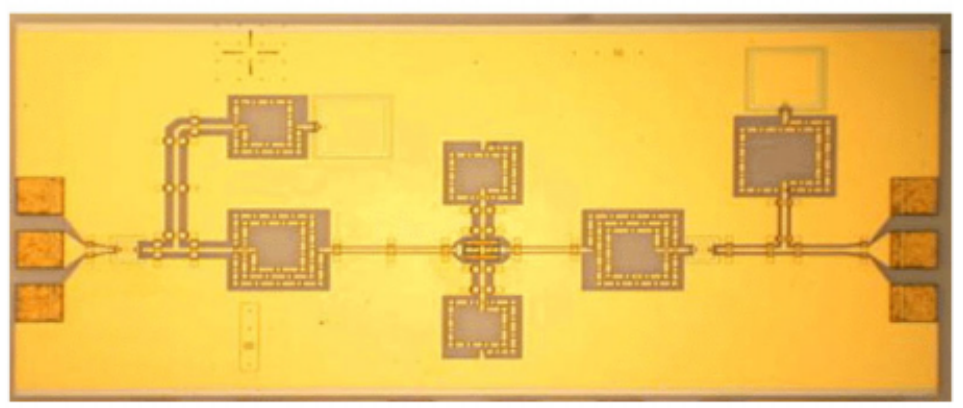

(b) 


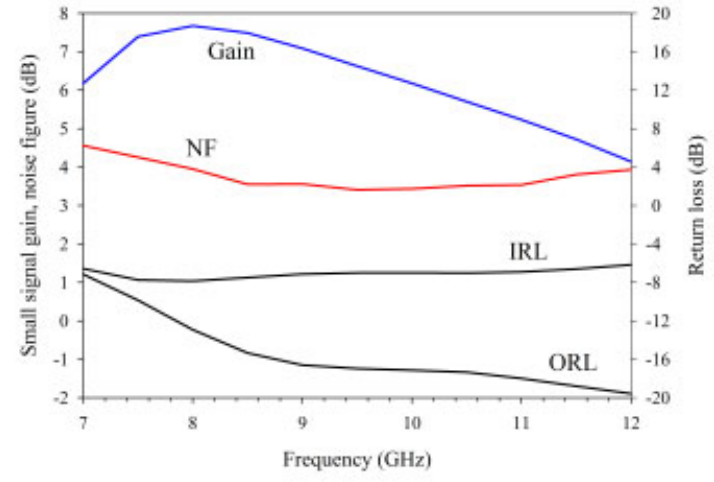

Fig. 4 Small signal and noise performance of the monolithic AlGaN/GaN HEMT-based LNA.

5 Summary A fully monolithic GaN-based X-band low noise amplifier employing 0.25- $\mu$ m gates has been reported. It was fabricated on $\mathrm{AlGaN} / \mathrm{GaN}$ HEMT layers grown on a SiC substrate. The LNA MMIC demonstrated broadband performance with $3.5 \mathrm{~dB}$ noise figure and $7.5 \mathrm{~dB}$ gain at $8.5 \mathrm{GHz}$. Further optimization of device structures and processing for low noise performance are expected to result in improved LNA performance. These results indicate the potential of GaN-based HEMTs for a fully integrated $\mathrm{Tx} / \mathrm{Rx}$ function for next-generation radar and communication systems.

Acknowledgements This work was supported by ONR under contract No. N00014-01-1-1000 (monitor: Dr. H. Dietrich) and contract No. N0014-1-1072 (monitor: Dr. H. Dietrich).

\section{References}

[1] S. T. Sheppard, K. Doverspike, W. L. Pribble, S. T. Allen, J. W. Palmour, L. T. Kehias, and T. J. Jenkins, IEEE Electron Device Lett. 20, 161 (1999).

[2] N. X. Nguyen, M. Micovic, W.-S. Wong, P. Hashimoto, L.-M. McCray, P. Janke, and C. Nguyen, Electron. Lett. 36, 468 (2000).

[3] V. Tilak, B. Green, V. Kaper, H. Kim, T. Prunty, J. Smart, J. Shealy, and L. Eastman, IEEE Electron Device Lett. 22, 504 (2001).

[4] A. Zhang, L. Rowland, E. Kaminsky, J. Tucker, J. Kretchmer, A. Allen, J. Cook, and B. Edward, Electron. Lett. 39, 245 (2003).

[5] Y. Ando, Y. Okamoto, H. Miyamoto, T. Nakayama, T. Inoue, and M. Kuzuhara, IEEE Electron Device Lett. 24, 289 (2003).

[6] Y.-F. Wu, A. Saxler, M. Moore, R. Smith, S. Sheppard, P. Chavarkar, T. Wisleder, and U. Mishra, IEEE Electron Device Lett. 25, 117 (2004).

[7] A. T. Ping, E. Piner, J. Redwing, M. A. Khan, and I. Adesida, Electron. Lett. 36, 175 (2000).

[8] N. X. Nguyen, M. Micovic, W.-S. Wong, P. Hashimoto, P. Janke, D. Harvey, and C. Nguyen, Electron. Lett. 36, 469 (2000).

[9] W. Lu, V. Kumar, R. Schwindt, E. Piner, and I. Adesida, Solid State Electronics 46, 1441 (2002).

[10] R. Welch, T. Jenkins, B. Neidhard, L. Kehias, T. Quach, P. Watson, R. Worley, M. Barsky, R. Sandhu, and M. Wojtowicz, in: IEEE GaAs IC Symposium Digest, Baltimore, Maryland, USA, 2001, (IEEE, Piscataway, 2001), pp. 153-155.

[11] H. Xu, C. Sanabria, A. Chini, S. Keller, U. K. Mishra, and R. A. York, IEEE Microwave and Wireless Components Lett. 14, 262, (2004).

[12] G. A. Ellis, J.-S. Moon, D. Wong, M. Micovic, A. Kurdoghlian, P. Hashimoto, and M. Hu, in: IEEE International Microwave Symposium Digest, Baltimore, Maryland, USA, 2004 (IEEE, Piscataway, 2004), pp. 153156.

[13] S. Cha, Y. H. Chung, M. Wojtowicz, I. Smorchkova, B. R. Allen, J. M. Yang, and R. Kagiwada, in: IEEE International Microwave Symposium Digest, Baltimore, Maryland, USA, 2004 (IEEE, Piscataway, 2004), pp. 829-832.

[14] D. Selvanathan, L. Zhou, V. Kumar, and I. Adesida, phys. stat. sol. (a) 194, 583 (2002).

(C) 2005 WILEY-VCH Verlag GmbH \& Co. KGaA, Weinheim 